\title{
In situ NMR observation of the lithium extraction/insertion from LiCoO2 cathode
}

\section{$\operatorname{AUTHOR}(\mathrm{S})$ :}

Shimoda, Keiji; Murakami, Miwa; Takamatsu, Daiko; Arai, Hajime; Uchimoto, Yoshiharu; Ogumi, Zempachi

\section{CITATION:}

Shimoda, Keiji ...[et al]. In situ NMR observation of the lithium

extraction/insertion from LiCoO2 cathode. Electrochimica Acta 2013, 108: 343-349

\section{ISSUE DATE:}

2013-10

URL:

http://hdl.handle.net/2433/179277

\section{RIGHT:}

(c) 2013 The Authors. Published by Elsevier Ltd.; This is an open-access article distributed under the terms of the Creative Commons Attribution-NonCommercial-No Derivative Works License, which permits non-commercial use, distribution, and reproduction in any medium, provided the original author and source are credited. 


\title{
In situ NMR observation of the lithium extraction/insertion from $\mathrm{LiCOO}_{2}$ cathode $^{\text {is }}$
}

\author{
Keiji Shimoda a,*, Miwa Murakami ${ }^{a}$, Daiko Takamatsu ${ }^{a}$, Hajime Arai $^{\mathrm{a}}$, \\ Yoshiharu Uchimoto ${ }^{\mathrm{b}}$, Zempachi Ogumi ${ }^{\mathrm{a}}$
}

a Office of Society-Academia Collaboration for Innovation, Kyoto University, Uji, Kyoto 611-0011, Japan

${ }^{\mathrm{b}}$ Graduate School of Human and Environment Studies, Kyoto University, Kyoto 606-8501, Japan

\section{A R T I C L E I N F O}

Article history:

Received 27 March 2013

Received in revised form 13 June 2013

Accepted 18 June 2013

Available online $\mathrm{xxx}$

Keywords:

Nuclear magnetic resonance

In situ NMR

Lithium-7

Lithium ion battery

$\mathrm{LiCoO}_{2}$ cathode

Lithium dendrite

\begin{abstract}
A B S T R A C T
Rechargeable lithium-ion batteries (LIBs) are currently accepted to be one of the most suitable energy storage resources in portable electronic devices because of their high gravimetric and volumetric energy density. To understand the behavior of $\mathrm{Li}^{+}$ions on electrochemical lithium extraction/insertion process, we performed in situ ${ }^{7} \mathrm{Li}$ nuclear magnetic resonance (NMR) measurements for $\mathrm{LiCoO}_{2}$ cathode in a plastic cell battery, and the spectral evolutions of the ${ }^{7} \mathrm{Li} \mathrm{NMR} \mathrm{signal} \mathrm{of} \mathrm{Li}_{x} \mathrm{CoO}_{2}(0 \leq x \leq 1)$ were well investigated. Very narrow solid solution region of $\mathrm{Li}_{x} \mathrm{CoO}_{2}(\sim 0.99 \leq x<1)$ was explicitly defined from the large intensity reduction of $\mathrm{LiCoO}_{2}$ signal at $\sim 0 \mathrm{ppm}$, which is related to the localized nature of the electronic spin of paramagnetic $\mathrm{Co}^{4+}$ ion formed at the very early delithiation stage. With further decreasing the signal intensity of $\mathrm{LiCoO}_{2}$, a Knight-shifted signal corresponding to an electrically conductive $\mathrm{Li}_{x} \mathrm{CoO}_{2} \mathrm{phase}$ emerged at $x=0.97$, which then monotonously decreased in intensity for $x<0.75$ in accordance with the electrochemical lithium de-intercalation from $\mathrm{Li}_{x} \mathrm{CoO}_{2}$. These observations acquired in situ fully confirm the earlier studies obtained in ex situ measurements, although the present study offers more quantitative information. Moreover, it was shown that the peak position of the NMR shift for $\mathrm{Li}_{x} \mathrm{CoO}_{2}$ moved as a function of lithium content, which behavior is analogous to the change in its $c$ lattice parameter. Also, the growth and consumption of dendritic/mossy metallic lithium on the counter electrode was clearly observed during the charge/discharge cycles.
\end{abstract}

(c) 2013 The Authors. Published by Elsevier Ltd. All rights reserved.

\section{Introduction}

Rechargeable lithium-ion batteries (LIBs) have attracted much attention as a preferred energy storage resource not only for portable electronics devices but also for electric vehicles, which further demand high voltage, high capacity, long cycle life, high rate performance, and safety. To enhance such battery performances, it is necessary to follow the chemical state of the positive/negative electrode materials and electrolyte solution in electrochemical operation. Considerable efforts have been made for understanding what occurs during the electrochemical reactions by in situ techniques using X-ray diffraction (XRD) and X-ray absorption spectroscopy (XAS). Layered $\mathrm{LiCoO}_{2}$-based materials are widely

\footnotetext{
This is an open-access article distributed under the terms of the Creative Commons Attribution-NonCommercial-No Derivative Works License, which permits non-commercial use, distribution, and reproduction in any medium, provided the original author and source are credited.

* Corresponding author at: Center for Advanced Science and Innovation, Kyoto University, Gokashou, Uji 611-0011, Japan. Tel.: +81 77438 4967; fax: +81774384996.

E-mail address: k-shimoda@saci.kyoto-u.ac.jp (K. Shimoda).
}

used as a positive electrode in commercially available LIBs, and several authors reported its changes in crystal structure and electronic structure on electrochemical cycling [1-6]. In situ XRD measurements showed the multistep phase transitions in $\mathrm{Li}_{x} \mathrm{CoO}_{2}$ $(x<1.0)$ during electrochemical delithiation [1-4]. The first transition occurs at a characteristic voltage plateau of $\sim 3.9 \mathrm{~V}$ versus $\mathrm{Li} / \mathrm{Li}^{+}$ $\left(0.75 \leq x \leq 0.93\right.$ in $\left.\mathrm{Li}_{x} \mathrm{CoO}_{2}\right)$, where a newly appeared rhombohedral phase (called O3-II) coexists with the pristine $\mathrm{LiCoO}_{2}(\mathrm{O} 3-\mathrm{I})$. The O3-II phase is a single component in the region of $0.5<x \leq 0.75$. At $x \approx 0.5$ corresponding to a voltage of $4.2 \mathrm{~V}$, the 03 -II phase transforms to a monoclinic phase, where the in-plane Li and its vacancy positions align with each other in an ordered sequence. This monoclinic phase is short-lived and transformed again to a rhombohedral O3-II phase upon further lithium extraction. Next phase separation occurs at the voltage of $\sim 4.6 \mathrm{~V}$. The new phase is called H1-3, which is considered to be a hybrid of two layers, O3-type stacking $\mathrm{Li}_{x} \mathrm{CoO}_{2}$ layer and $\mathrm{CoO}_{2}(\mathrm{O} 1)$ layer. Finally, the $\mathrm{H} 1-3$ phase totally becomes $\mathrm{CoO}_{2}$ at $x \approx 0$. Recently, in situ neutron diffraction (ND) technique was developed and also confirmed the coexistence of O3-I and II phases at $3.9 \mathrm{~V}$ plateau and the formation of monoclinic phase at $x \approx 0.5$ [5]. These studies showed the expansion of $c$-axis of the layered $\mathrm{Li}_{x} \mathrm{CoO}_{2}$ with the lithium extraction from $\mathrm{O} 3-\mathrm{I}$, 
O3-II, to monoclinic phase. While XRD and ND provide crystal structure information, XAS offers valence state information on a specific atom. Nakai et al. have reported an in situ XAS study of $\mathrm{Li}_{x} \mathrm{CoO}_{2}$ at Co $\mathrm{K}$-edge [6]. The positive shift of the main peak in the X-ray absorption near edge structure (XANES) region was observed with the lithium extraction from $x=1$ to 0.2 , which would correspond to the valence change (oxidation) between $\mathrm{Co}^{3+}$ in $\mathrm{LiCoO}_{2}$ and $\mathrm{Co}^{4+}$ in $\mathrm{CoO}_{2}$ [7].

It is very important to directly observe the $\mathrm{Li}^{+}$ions moving in the battery cell, which is hardly attained or technically demanding with XRD, ND or XAS methods. Nuclear magnetic resonance (NMR) spectroscopy is a promising tool for this purpose. ${ }^{6,7} \mathrm{Li}$ NMR spectra have been acquired ex situ for the LIB positive and negative electrode materials to obtain structural information on $\mathrm{Li}^{+}$ions [8-23]. $\mathrm{A}^{7} \mathrm{Li}$ magic-angle spinning (MAS) NMR study revealed that the $\mathrm{Li}_{x} \mathrm{CoO}_{2}$ O3-II phase obtained by the electrochemical delithiation showed a Knight shift at 60-100 ppm [10]. Recently, some researchers have tackled on real time NMR investigations during electrochemical cycling [24-32]. Although in situ NMR measurement is performed under static condition, and therefore it is not expected to give high-resolution signals as in MAS technique, this technique has an advantage that the spectral (structural) changes can be evaluated quantitatively in a single experiment in a non-destructive manner. This may clarify thermodynamically unstable transient phases during electrochemical cycling (non-equilibrium behavior). Also, it is not necessary to consider undesirable contaminations and possible lithium loss coming from disassembling the batteries and rinsing the electrodes, which are more or less inevitable for ex situ measurements. In situ NMR measurements have been reported mostly for anode materials. Letellier et al. showed that $\mathrm{Li}^{+}$ions were intercalated in graphitic carbon with a successive staging from $\mathrm{LiC}_{36}, \mathrm{LiC}_{27}, \mathrm{LiC}_{18}, \mathrm{LiC}_{12}$, and finally to $\mathrm{LiC}_{6}$, whereas they were intercalated in disorganized carbon in a different manner [25-28]. Similarly, Grey's group has indicated the lithium insertion into the silicon electrode [29]. However, there has been almost no report focusing on the lithium extraction/insertion behavior of the cathode materials in situ upon charging/discharging reactions because it is difficult to clearly observe their very broad signals in static NMR spectra [32]. We here performed in situ ${ }^{7} \mathrm{Li} \mathrm{NMR}$ measurements for a $\mathrm{Li}|| \mathrm{LiCoO}_{2}$ plastic cell battery during the electrochemical charge/discharge cycling, and successfully observed the lithium extraction/insertion behavior of the $\mathrm{LiCoO}_{2}$ cathode material by optimizing the cell components and by using relatively high magnetic field. The dynamic growth and consumption of dendritic/mossy lithium on the Li anode was also clearly shown during the cycles.

\section{Experimental}

\subsection{Electrochemical cell}

We used a commercial $\mathrm{LiCoO}_{2}$ (average particle size of $12 \mu \mathrm{m}$, $\mathrm{Li} / \mathrm{Co}$ ratio $=1.01$, Nichia) as a cathode active material. A mixture of $\mathrm{LiCoO}_{2}$ powder, acetylene black (Denki Kagaku Kogyo), and polyvinylidene difluoride (PVDF, Kureha) with a weight ratio of 80:10:10 was spread with N-methylpyrrolidone (NMP) onto aluminum foil, and then dried at $80^{\circ} \mathrm{C}$ under vacuum overnight to constitute a positive electrode. The electrode was cut with the dimensions of $15 \mathrm{~mm} \times 5 \mathrm{~mm}$, which included $\sim 13 \mathrm{mg}$ of $\mathrm{LiCoO}_{2}$. A foil of metallic lithium $(0.2 \mathrm{~mm}$ in thickness, $>99.9 \%$, Honjo Metal) was used as a counter electrode. We used the Celgard 2500 as a separator. The electrolyte applied here was $1 \mathrm{M} \mathrm{LiClO}_{4}$ dissolved in anhydrous ethylene carbonate (EC) and diethyl carbonate (DEC) with a volumetric ratio of 1:1 (Kishida Chemical). Aluminum and copper strips were used as current collectors for positive and negative electrodes, respectively. Then, the cell components were assembled together and soaked with the liquid electrolyte in a transparent silica-deposited gas-barrier film cell, which was hermetically sealed in an argon-filled glove box (<1.0 ppm oxygen). The assembly was designed according to the previous studies (Fig. S1) [28].

\subsection{Electrochemical measurements}

The charge-discharge curves were measured at room temperature on an automatic cycling/data recording system (HJ1001SD8, Hokuto Denko) in a galvanostatic operating mode. Two different runs were performed; the first run was carried out at a voltage window between 3.0 and $4.3 \mathrm{~V}$ for 3 charging/discharging cycles to examine the reversibility of the NMR signals in the cell during cycles. The charging was done with a rate of $0.12 \mathrm{C}(32.0 \mathrm{~mA} / \mathrm{g})$ up to $4.3 \mathrm{~V}$, at which voltage a short constant voltage process was included (total of $5 \mathrm{~h}$ ). Similarly, the discharging was done with a rate of $32.0 \mathrm{~mA} / \mathrm{g}$ down to $3.0 \mathrm{~V}$ with a constant voltage process (total of $5 \mathrm{~h}$ ). The second run was separately carried out up to $5.0 \mathrm{~V}$ with a slower rate of $0.02 \mathrm{C}(5.5 \mathrm{~mA} / \mathrm{g})$ for $50 \mathrm{~h}$ for a charging process to achieve the complete delithiation from $\mathrm{LiCoO}_{2}$.

\subsection{In situ ${ }^{7} \mathrm{Li} N M R$}

The plate-like battery cell was packed into a polyethylene tube, which was horizontally placed in the center of $10 \mathrm{~mm}$ diameter solenoidal coil of a wide-bore static probe. The ${ }^{7} \mathrm{Li}$ NMR measurements were carried out at room temperature on a JNM-ECA600 spectrometer (JEOL) at a magnetic field of $14.1 \mathrm{~T}\left({ }^{7} \mathrm{Li}\right.$ working frequency of $233.2 \mathrm{MHz}$ ). A low-pass filter was connected on the wire for battery cycling to suppress the undesirable high-frequency noise components and improve the signal-to-noise ratio of the NMR signals. The battery cell was cycled galvanostatically during the spectral acquisitions.

A single pulse sequence was used with the $\pi / 2$ pulse width of $3.5 \mu \mathrm{s}$ optimized for $\mathrm{LiCoO}_{2}$ and a preacquisition delay of $5.0 \mu \mathrm{s}$ was applied prior to a relaxation delay of $1 \mathrm{~s}$. It should be noted that the delay of $5.0 \mu \mathrm{s}$ before the signal acquisition, which is required to suppress probe ringing background, lead to a small signal loss of $\sim 5 \%$ compared to the acquisition without the delay, but we emphasized that a series of spectra acquired in a single experiment can be treated quantitatively. We also note that spectra acquired with single pulse and echo sequences were essentially the same in linewidth and shape, indicating that the broad signal of $\mathrm{LiCoO}_{2}$ is fully observable, but with higher intensity, by using the single pulse sequence. A total of 880 scans were collected for each spectrum. It takes $\sim 15$ min over which the acquired spectrum is averaged, corresponding to the change of $0.03 \mathrm{Li}$ and $0.005 \mathrm{Li}$ per $\mathrm{LiCoO}_{2}$ in the first and second run, respectively. Each acquisition was automatically run every half an hour. $1 \mathrm{M} \mathrm{LiCl}$ aqueous solution was used as ${ }^{7} \mathrm{Li}$ chemical shift reference at $0.0 \mathrm{ppm}$.

\section{Results and discussion}

\subsection{Spectral evolutions on charging/discharging cycles}

Fig. 1 shows the charge/discharge profile up to $4.3 \mathrm{~V}$ during 3 cycles. The capacities obtained during the cycles were 151/146 mAh/g (1st charging/discharging cycle), 147/144 mAh/g (2nd cycle), and 145/141 mAh/g (3rd cycle), respectively, indicating that about a half of $\mathrm{Li}^{+}$ion $(0.52-0.55)$ in $\mathrm{LiCoO}_{2}$ were reversibly involved in the electrochemical reactions between 3.0 and $4.3 \mathrm{~V} .{ }^{7} \mathrm{Li}$ NMR spectra of the battery cell on the first charging/discharging cycle are shown in Fig. 2. A sharp peaks at $\sim 0$ and $\sim 250$ ppm are assigned to $\mathrm{LiClO}_{4}$ in the liquid electrolyte and $\mathrm{Li}$ metal as negative 


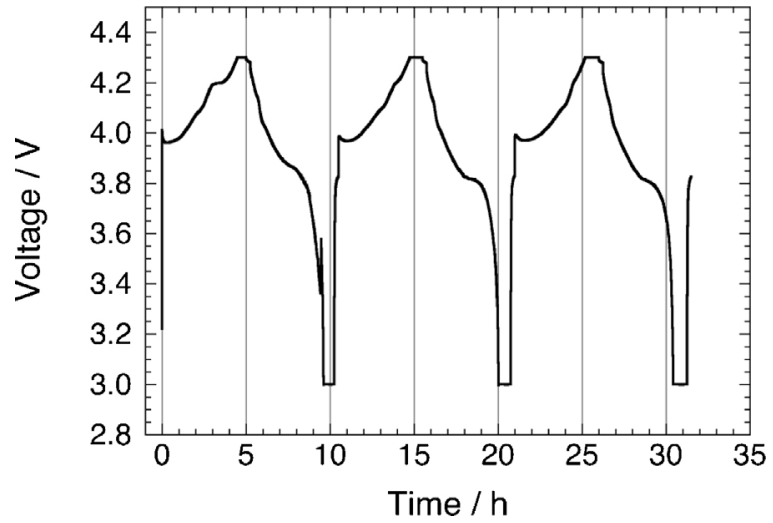

Fig. 1. Electrochemical profile of the $\mathrm{Li}|| \mathrm{LiCoO}_{2}$ plastic cell battery during 3 charge/discharge cycles.

electrode, respectively. Here, it is noted that the radio frequency (rf) field applied to excite nuclear spin can penetrate into the bulk metal in a finite depth (skin-depth problem) [33]. In our experiments, the skin-depth of the ${ }^{7} \mathrm{Li}$ rf pulse was estimated to be $\sim 8.4 \mu \mathrm{m}$ [30], indicating that only the surface part of the lithium electrode could be excited for NMR signal detection. The broad peak centered at $\sim 0 \mathrm{ppm}$, which covers from -100 to $100 \mathrm{ppm}$, is found to be the $\mathrm{LiCoO}_{2}$ active material in the positive electrode [8]. We here emphasize that the ${ }^{7} \mathrm{Li}$ signal of the cathode material can be successfully observed, and therefore that all the lithium components including cathode, anode, and electrolyte in the cell are visible simultaneously using ${ }^{7} \mathrm{Li}$ NMR spectroscopy. Fig. 2a indicates that the intensity of $\mathrm{LiCoO}_{2}$ peak decreases on charging
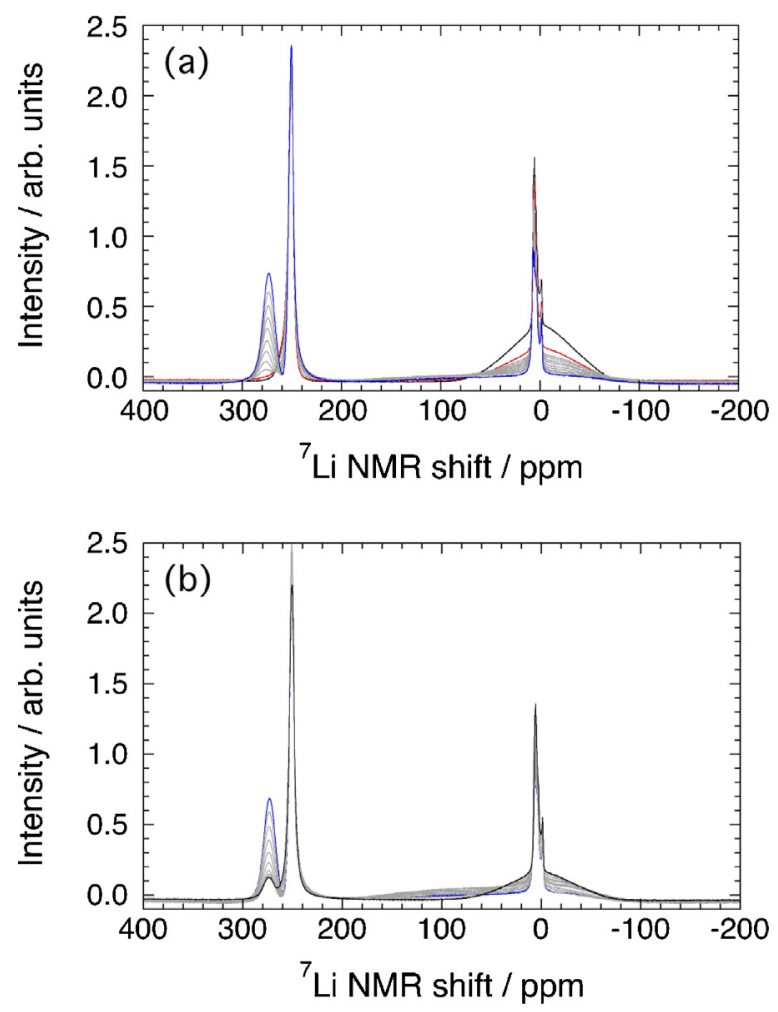

Fig. 2. In situ ${ }^{7} \mathrm{Li} \mathrm{NMR}$ spectra of the $\mathrm{Li}|| \mathrm{LiCoO}_{2}$ plastic cell battery during the first charge/discharge cycle. (a) Charging; $x=1.0$ prior to electrochemical measurements (black line), 0.97 (red) to 0.45 (blue), and (b) discharging; from 0.45 (blue) to 0.98 (black). The other spectra were drawn in gray lines. (For interpretation of the references to color in this figure legend, the reader is referred to the web version of the article.) process. This is consistent with the electrochemical lithium extraction from $\mathrm{LiCoO}_{2}$. It is noteworthy that the $\mathrm{LiCoO}_{2}$ peak intensity immediately decreases to about a half of its original height on the first 15 min of charging process (corresponding to $\mathrm{Li}_{0.97} \mathrm{CoO}_{2}$, from black to red spectra in Fig. 2a) and then slowly decreases after the next $15 \mathrm{~min}$. Here, it should be mentioned that the spectrum acquired for $15 \mathrm{~min}$ (corresponding to $\Delta x=0.03 \mathrm{Li}$ in the first run) shows the average spectrum during 880 transients. Therefore, the spectrum accumulated during the first $15 \mathrm{~min}$ corresponds to the average on decreasing $x$ from 1.00 to 0.97 , and might be described as $\mathrm{Li}_{0.97 \leq x<1.00} \mathrm{CoO}_{2}$ in a precise sense. However, we use the notation $\mathrm{Li}_{0.97} \mathrm{CoO}_{2}$ for simplification keeping in mind that the subscript value has a margin of $\Delta x \sim 0.03$ above the value. The growth of a broad signal was also observed at $\sim 90 \mathrm{ppm}$, and this will be discussed in the next section. Concurrently, a new peak grows on the left side of the anodic lithium peak, which has been attributed to the dendritic and/or mossy metallic lithium on the lithium electrode [30]. Grey and coworkers have showed the peak shift of metallic lithium from 272 to $244 \mathrm{ppm}$ with the lithium metal strip placed at the varying angle from $0^{\circ}$ (vertical setting in the coil) to $90^{\circ}$ (horizontal) with respect to the external magnetic field $B_{0}$ [34]. Such shifts in peak position are considered to come from the bulk magnetic susceptibility (BMS) effect that depends on the bulk shape (flat or spherical) of a metallic or paramagnetic material with respect to $B_{0}$. It is noted that the battery cell is horizontally placed in the first run, and therefore the lithium electrode gives the Knight shift signal at $\sim 250 \mathrm{ppm}$ (Fig. S2). The newly appeared lithium peak has the signal at $\sim 270 \mathrm{ppm}$, possibly indicating that the dendritic/mossy lithium is vertically attached on the horizontally placed lithium electrode as illustrated in Ref. [30]. It should be stressed that this is a clear indication of the dendritic/mossy lithium, which grows on the negative electrode during the charging process.

On discharging process, the reactions seem to be reversible; the broad peak centered at $\sim 0 \mathrm{ppm}$ increases in intensity with decreasing the $270 \mathrm{ppm}$ peak intensity (Fig. 2b). This indicates that the $\mathrm{Li}^{+}$ions are re-inserted in the layered $\mathrm{Li}_{x} \mathrm{CoO}_{2}$ structure, while the dendritic/mossy lithium on the surface of Li electrode would be dissolved into the liquid electrolyte. The spectral changes during the second and third charging/discharging cycles are still reversible and consistent with the electrochemical profile (Fig. S3). It should be noted that the spectra of $\mathrm{LiCoO}_{2}$ at the end of each discharging process did not fully recover the intensity of the pristine $\mathrm{LiCoO}_{2}$ observed before the electrochemical measurement, but similar to the one during the first 15 min of charging process, which corresponds to the lithium extraction of $\sim 0.03$ from $\mathrm{LiCoO}_{2}$, i.e., $\mathrm{Li}_{0.97} \mathrm{CoO}_{2}$ in the positive electrode (Fig. S3h). This fact suggests that the discharged $\mathrm{Li}_{\sim 1.00} \mathrm{CoO}_{2}$ holds a very small amount of paramagnetic $\mathrm{Co}^{4+}$, and that some $\mathrm{Li}^{+}$ions $(\leq 0.03 \mathrm{Li})$ cannot be inserted back to be $\mathrm{Li}_{1.00} \mathrm{CoO}_{2}$ on discharging, being consistent with the irreversible capacity estimated from the electrochemical measurement. The possible deposition of solid electrolyte interface (SEI) on $\mathrm{Li}_{x} \mathrm{CoO}_{2}$ can cause an irreversible lithium loss and imperfect lithium re-insertion to $\mathrm{Li}_{x} \mathrm{CoO}_{2}$. Alternatively, the low electrical conductivity of $\mathrm{Li}_{1.00} \mathrm{CoO}_{2}$ (non-metallic nature [10]) may prevent the further insertion of $\mathrm{Li}^{+}$ions into $\mathrm{Li}_{\sim 0.97} \mathrm{CoO}_{2}$. It is emphasized that in situ ${ }^{7} \mathrm{Li}$ NMR enables us to obtain unique information about such a small amount of lithium deficiency in $\mathrm{LiCoO}_{2}$ on lithium reinsertion, which information is not accessible with XRD and ND. In turn, we found that a small amount of dendritic/mossy lithium is left at the end of each discharging process, and that increases with increasing cycle number (Fig. 3). The amount of dendritic/mossy lithium remains almost constant for $12 \mathrm{~h}$ after the electrochemical measurement. These results indicate that the dendritic/mossy lithium builds up dynamically with cycling the charge/discharge processes. 


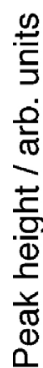

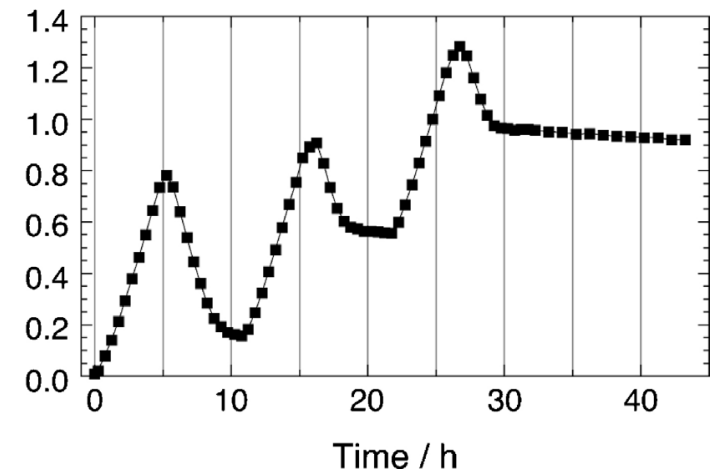

Fig. 3. Peak height evolution of the ${ }^{7} \mathrm{Li}$ signal for dendritic/mossy lithium during the charge/discharge cycles.

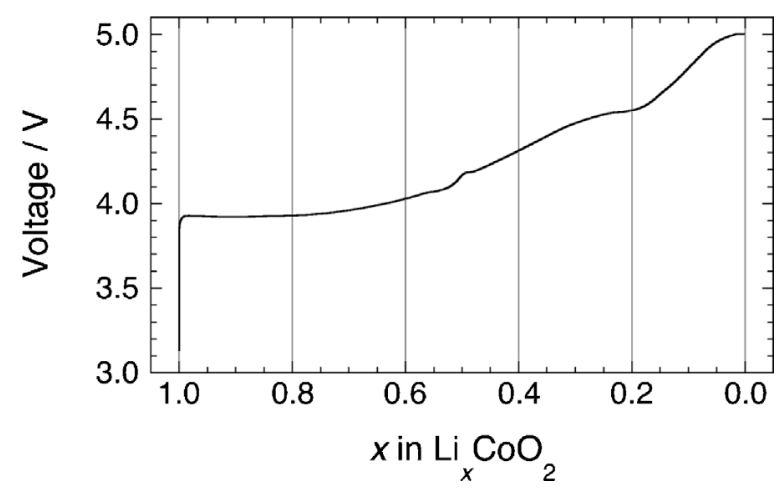

Fig. 4. Electrochemical profile of the plastic cell battery on charging process up to $5.0 \mathrm{~V}$.

\subsection{Spectral evolutions of $\mathrm{LiCOO}_{2}$ cathode on charging process up to $5.0 \mathrm{~V}$}

The detailed spectral changes in $\mathrm{LiCoO}_{2} / \mathrm{Li}_{x} \mathrm{CoO}_{2}$ signals were examined with decreasing $x$ from 1 to 0 with a rate of $0.02 \mathrm{C}$ in a separate run. The charging profile is shown in Fig. 4, which is similar to the previous studies [3,4]. Fig. 5 shows the spectral evolution of $\mathrm{LiCoO}_{2} / \mathrm{Li}_{x} \mathrm{CoO}_{2}$ signals in the in situ ${ }^{7} \mathrm{Li}$ NMR spectra acquired at horizontal cell setting. Same measurements were performed at vertical setting in a separate run, and the spectra are shown in Fig. 6. The spectral evolutions in Figs. 5 and 6 are significantly different because of the BMS effect of electric conductive $\mathrm{Li}_{x} \mathrm{CoO}_{2}$. We found that the spectral separation between $\mathrm{LiCoO}_{2}$ and $\mathrm{Li}_{x} \mathrm{CoO}_{2}$ signals was clear at vertical setting. Therefore, we will discuss the structural changes of $\mathrm{LiCoO}_{2}$ cathode material based on the spectral evolutions shown in Fig. 6. As observed in the 3-cycled run shown in Fig. 2, the peak intensity of $\mathrm{LiCoO}_{2}$ immediately decreases to about a half of its original height on the first $45 \mathrm{~min}$ ( 2 acquisitions) of the charging process (Figs. 5a and 6a). This time period corresponds to the build-up of the charging profile from $\sim 3.13 \mathrm{~V}$ (open circuit voltage) to $3.92 \mathrm{~V}$ (plateau voltage for $03-\mathrm{I} / \mathrm{II}$ biphasic region $[1,35]$ ), and the lithium removal of $\sim 0.01$, i.e., $\mathrm{Li}_{0.99} \mathrm{CoO}_{2}$ in the positive electrode. The difference spectrum between the first 2 acquisitions showed a broad peak similar to that of pristine $\mathrm{LiCoO}_{2}$, indicating that the intensity loss is clearly related to the delithiation of $\mathrm{LiCoO}_{2}$. Ménétrier et al. have performed ex situ ${ }^{7} \mathrm{Li}$ MAS NMR measurements for the electrochemically delithiated $\mathrm{Li}_{x} \mathrm{CoO}_{2}$, and reported a similar intensity reduction for the samples with $0.94 \leq x<1.0$ [10]. It is considered that the diamagnetic $\mathrm{Co}^{3+}$ ion (electronic configuration, $3 d^{6}$ ) should be oxidized to paramagnetic $\mathrm{Co}^{4+}$ ion $\left(3 d^{5}\right)$ for the charge compensation on the lithium extraction from $\mathrm{LiCoO}_{2}$. The paramagnetic $\mathrm{Co}^{4+}$ has the unpaired electronic spin(s), which induces the spin density transferred on Li nuclei near the $\mathrm{Co}^{4+}$ ion
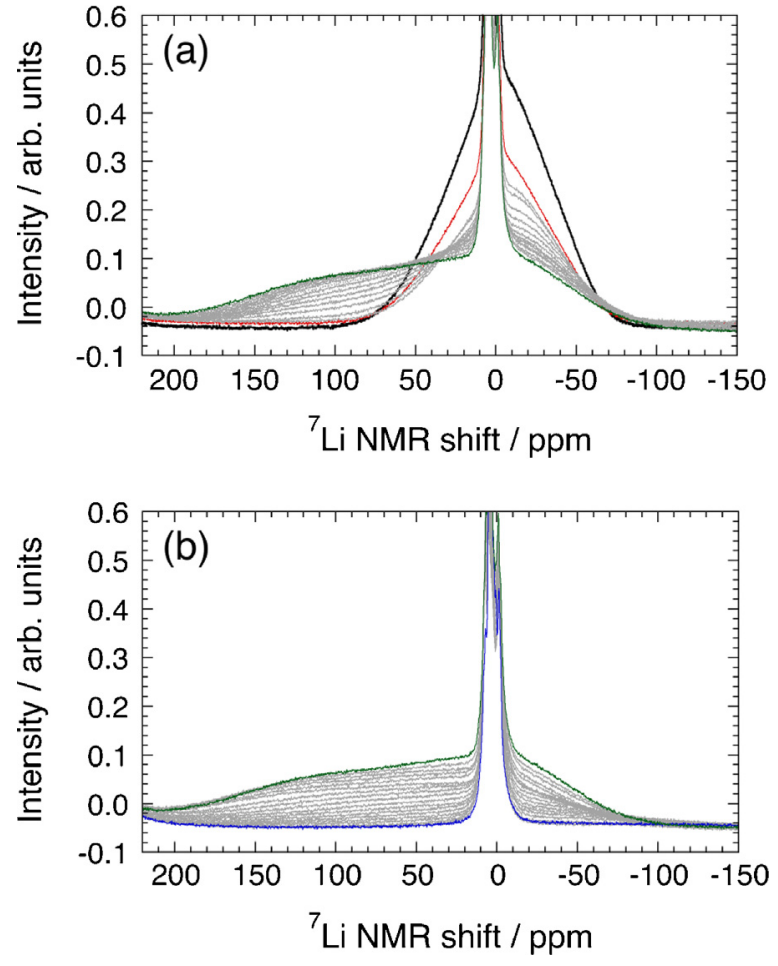

Fig. 5. In situ ${ }^{7} \mathrm{Li}$ NMR spectra acquired at horizontal setting for $\mathrm{Li}_{x} \mathrm{CoO}_{2}$ cathode material $(0 \leq x \leq 1)$ during the charging process from (a) $x=1.0$ (black line), 0.99 (red) to 0.74 (green), and (b) from 0.72 (green) to 0.0 (blue). The other spectra were drawn in gray lines. (For interpretation of the references to color in this figure legend, the reader is referred to the web version of the article.)
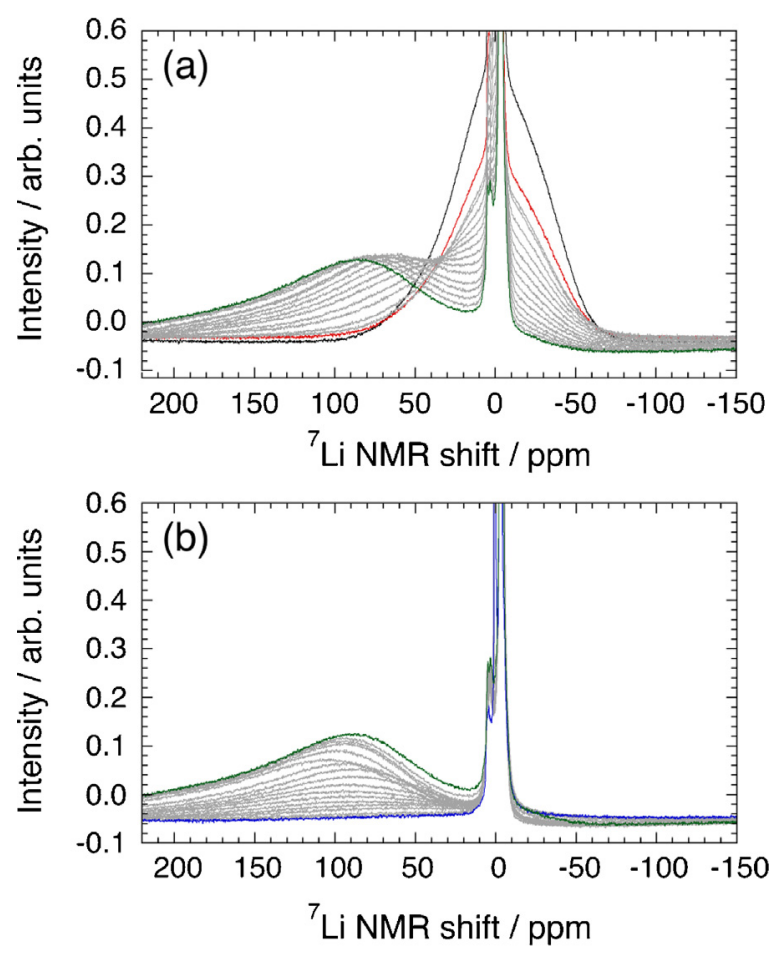

Fig. 6. In situ ${ }^{7} \mathrm{Li}$ NMR spectra acquired at vertical setting for $\mathrm{Li}_{x} \mathrm{CoO}_{2}$ cathode material $(0 \leq x \leq 1)$ during the charging process from (a) $x=1.0$ (black line), 0.99 (red) to 0.74 (green), and (b) from 0.72 (green) to 0.0 (blue). (For interpretation of the references to color in this figure legend, the reader is referred to the web version of the article.) 

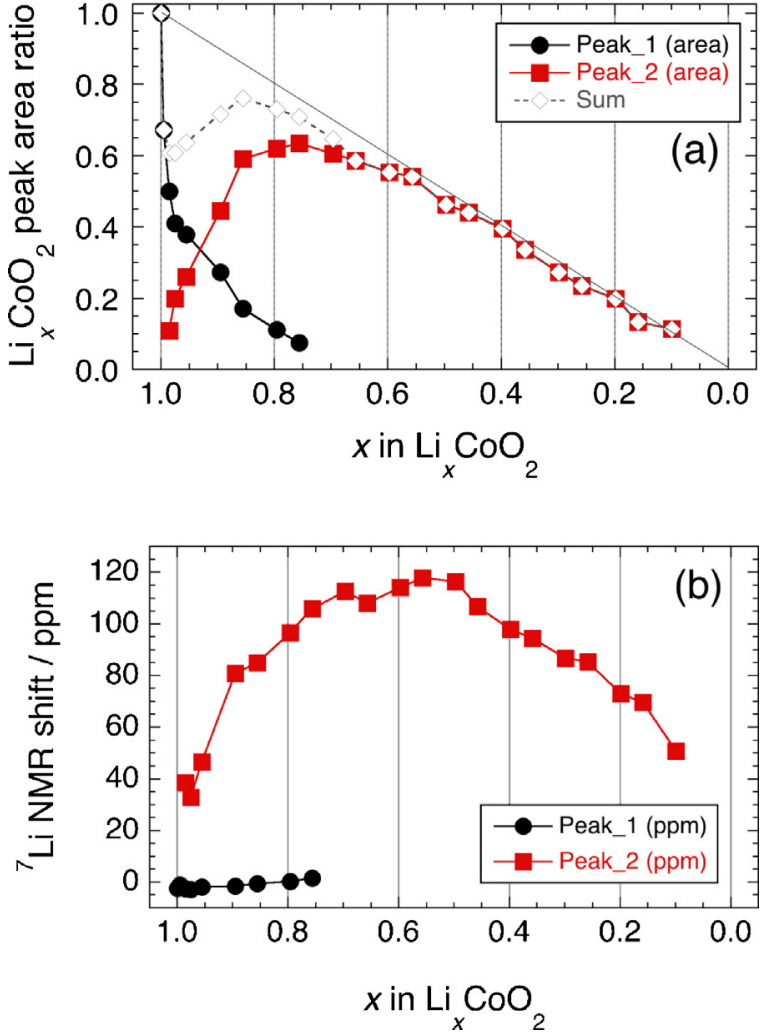

Fig. 7. (a) Peak area ratio and (b) peak position of the deconvolved $\mathrm{LiCoO}_{2} / \mathrm{Li}_{x} \mathrm{CoO}_{2}$ signals in the vertical setting ${ }^{7} \mathrm{Li}$ NMR spectra as a function of lithium content $x$ in $\mathrm{Li}_{x} \mathrm{CoO}_{2}$ (Peak_1: $\mathrm{LiCoO}_{2}$ component, Peak_2: $\mathrm{Li}_{x} \mathrm{CoO}_{2}$ component).

$[10,16]$. This would cause a strong transferred hyperfine interaction and a severe electron-nuclear dipolar interaction on a Li nucleus, which involves the apparent ${ }^{7} \mathrm{Li}$ intensity loss. The large reduction

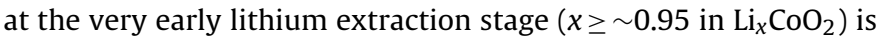
believed to be due to the localized nature of the electron on $\mathrm{Co}^{4+}$ and its nearby $\mathrm{Li}^{+}$ions at this stage, which would reflect the very narrow solid solution region of $\mathrm{LiCoO}_{2}$ O3-I phase [10].

With further lithium removal from $\mathrm{Li}_{x} \mathrm{CoO}_{2}$, a new broad signal centered at $\sim 90 \mathrm{ppm}$ appears in accordance with the intensity decreases of $\mathrm{LiCoO}_{2}$ signal (Fig. 6a) [8]. Fig. 7a shows the peak area ratio of the $\sim 0 \mathrm{ppm}$ - and $\sim 90 \mathrm{ppm}$-centered signals by fitting the spectra (acquired at vertical setting) with one and two pseudo-Voigt functions for each (the fitting includes 8 additional components for the overlapping electrolyte and metallic lithium signals; examples of the spectral deconvolution are shown in Fig. S4, and the details are described in its caption). The new signal increased in intensity with the lithium removal down to $x \approx 0.75$, whereas the $\mathrm{LiCoO}_{2}$ signal continued to decrease. According to Ménétrier et al., the new signal can be associated with the $\mathrm{Li}_{x} \mathrm{CoO}_{2} \mathrm{O} 3$-II phase [10]. This phase shows the Knight shift above $60 \mathrm{ppm}$ associated with its high electrical conductivity, indicating the metallic behavior of $\mathrm{Li}^{+}$ions at this stage [10]. Fig. 7a suggests the coexistence of O3-I $\left(\mathrm{LiCoO}_{2}\right)$ and $\mathrm{O} 3-\mathrm{II}\left(\mathrm{Li}_{x} \mathrm{CoO}_{2}\right)$ phases in the region of $\sim 0.75 \leq x<0.99$, supporting the previous studies $[1-4,10,35]$. An isosbestic point observed in the spectra for $0.86 \leq x \leq 0.98$ is also a clear indication of the coexistence of these two phases (Fig. 6a). It is interesting to note that the total ${ }^{7} \mathrm{Li}$ signal, which had been lost at $x \approx 0.99$, seems recovered in this electrochemical stage $(\sim 0.75 \leq x<0.99$ in Fig. $7 a)$. This comes from the intensity increase of the Knight shift signal. This indicates that the localized nature of electronic spins, which causes the apparent signal loss due to the strong dipolar interactions, changes to the delocalized one of conductive electrons, leading to the apparent re-increase of the total ${ }^{7} \mathrm{Li}$ signal [10].

$\mathrm{Li}_{x} \mathrm{CoO}_{2}$ becomes a single component for $x<0.75$. This phase starts to monotonically decrease in intensity with further delithiation (Figs. $6 \mathrm{~b}$ and $7 \mathrm{a}$ ). The signal reduction is consistent with decreasing the lithium content in $\mathrm{Li}_{x} \mathrm{CoO}_{2}$ estimated from the electrochemical measurement, indicating that it is quantitative below $x \approx 0.75$. Such intensity changes of the NMR signals can be quantitatively evaluated in principle in a suite of in situ measurements, demonstrating its advantage over the ex situ measurements.

Fig. $7 \mathrm{~b}$ plots the ${ }^{7} \mathrm{Li}$ NMR peak position of the $\mathrm{LiCoO}_{2} / \mathrm{Li}_{x} \mathrm{CoO}_{2}$ signals as a function of lithium content $x$ in $\mathrm{Li}_{x} \mathrm{CoO}_{2}$. It should be noted that the peak position may not strictly correspond to the isotropic shift especially for $\mathrm{Li}_{x} \mathrm{CoO}_{2}$ signal [8], because of its complex peak shape depending on the BMS effect with respect to $B_{0}$ as mentioned above [34]. We here discuss the evolution in peak position as a function of $x$. The peak position of the $\mathrm{Li}_{x} \mathrm{CoO}_{2}$ signal moves to higher frequency with decreasing $x$ down to 0.5 , which agrees with the previous ex situ NMR result $[8,10]$. However, it was shown that further delithiation lead to the peak shift of the $\mathrm{Li}_{x} \mathrm{CoO}_{2}$ signal to lower frequency. It is interesting to point out that the behavior of the ${ }^{7} \mathrm{Li}$ NMR shift for $\mathrm{Li}_{x} \mathrm{CoO}_{2}$ is analogous to the variation of the $c$ lattice parameter of $\mathrm{Li}_{x} \mathrm{CoO}_{2}$ as a function of $x$ reported by Amatucci et al. [2]. $\mathrm{Li}^{+}$ions are sandwiched in between $\mathrm{CoO}_{2}$ layers in $\mathrm{Li}_{x} \mathrm{CoO}_{2}$. It is therefore reasonable to consider that the ${ }^{7} \mathrm{Li}$ NMR shift of $\mathrm{Li}_{x} \mathrm{CoO}_{2}$ is correlated with the distance of the interlayer where $\mathrm{Li}^{+}$ions are placed (equal to one-third of the $c$ lattice parameter). The NMR peak shifts to higher frequency for $\mathrm{Li}_{x} \mathrm{CoO}_{2}$ at $x \leq \sim 0.8$ correspond to the fact that the interlayer $\mathrm{Li}^{+}$ions are monotonously removed from $\mathrm{Li}_{x} \mathrm{CoO}_{2}$ O3-II phase. The removal of $\mathrm{Li}^{+}$ions increases the electrostatic repulsion between oxygen atoms in adjacent $\mathrm{CoO}_{2}$ layers, which results in the expansion of $c$-axis of $\mathrm{Li}_{x} \mathrm{CoO}_{2}[2,10]$. We believe that the apparent NMR peak positions for $\mathrm{Li}_{x} \mathrm{CoO}_{2}$ at $0.95<x<0.99$ will be fictitious because the $\mathrm{LiCoO}_{2} / \mathrm{Li}_{x} \mathrm{CoO}_{2}$ signal separation was not well clear in this $x$ range, which may provide unreliable fitting results (see also Fig. S4b). The monoclinic phase at $x \approx 0.5$ has the maximum $c$ lattice parameter with the largest Knight shift. The monoclinic phase converts back to an O3-II phase for $x<0.5$, again decreasing the $c$ lattice parameter and the NMR peak position with further lithium removal. Unfortunately, it is not straightforward to explain the reason why the lattice parameter and the NMR shift seem correlated with each other. The Knightshifted nature of ${ }^{7} \mathrm{Li}$ signal of $\mathrm{Li}_{x} \mathrm{CoO}_{2}$ indicates that $\mathrm{Li} 2 s$ electrons partially act as delocalized conduction electrons. The Knight shift peak position is proportional to the number of the conduction electrons [25]. The higher frequency in Knight shift suggests the larger contribution of Li $2 s$ to conduction band, which may be related to the increasing electric conductivity of $\mathrm{Li}_{x} \mathrm{CoO}_{2}$ with decreasing $x$ down to $\sim 0.5$ [10]. If it is true, further delithiation should result in the decrease in electric conductivity.

The information of the electrolyte is also available in the in situ ${ }^{7} \mathrm{Li} \mathrm{NMR}$ measurements. The ${ }^{7} \mathrm{Li}$ signal of $\mathrm{LiClO}_{4}$ electrolyte shows a complicated feature because it is perturbed by the magnetic susceptibility of metallic lithium anode [33]. The signal did not show appreciable alterations in shape, position, and intensity up to $5.0 \mathrm{~V}$ (Figs. S5 and S6). This may indicate that the decomposition of liquid electrolyte is not significant (at least with respect to ${ }^{7} \mathrm{Li}$ ) below $5.0 \mathrm{~V}$ with a constant current mode, although more detailed work should be needed to confirm it definitely with longer relaxation delays (" $1 \mathrm{~s}$ ). We note that a new sharp peak was emerged in the electrolyte signal at $5.0 \mathrm{~V}$ with a constant voltage operation for several hours where the overall capacity was overcharged up to $\sim 300 \mathrm{mAh} / \mathrm{g}$ (Fig. S5d). This would be the indication of the decomposition of electrolyte and/or the concomitant possible formation of SEI. This suggests that although the less resolved nature of the signals should be taken into account in static NMR condition, the 
in situ NMR technique may be available for the investigation of the degradation of electrolyte and SEI formation during electrochemical operation, which gives useful information to improve the battery performance.

\section{Conclusions}

We performed in situ ${ }^{7} \mathrm{Li} \mathrm{NMR} \mathrm{measurements} \mathrm{for} \mathrm{a} \mathrm{Li}|| \mathrm{LiCoO}_{2}$ cell battery on electrochemical operation to investigate the spectral evolutions of the ${ }^{7} \mathrm{Li}$ NMR signal of $\mathrm{Li}_{x} \mathrm{CoO}_{2}(0 \leq x \leq 1)$ in detail. We observed the apparent ${ }^{7} \mathrm{Li}$ signal loss of $\mathrm{LiCoO}_{2}$ at the very early period of the charging process, which is considered due to the severe signal broadening by the electron-nuclear dipolar interactions on the Li nuclei nearby the paramagnetic $\mathrm{Co}^{4+}$ ions. In situ NMR measurements confirmed that the ${ }^{7} \mathrm{Li}$ signal is highly sensitive to the appearance of only a small amount of paramagnetic center. Based on the present in situ NMR results, we defined the very narrow O3-I region of $\mathrm{Li}_{x} \mathrm{CoO}_{2}(\sim 0.99 \leq x \leq 1)$. Below $x=0.99$, a broad Knight-shifted signal was emerged between 0 and $200 \mathrm{ppm}$. This signal showed a monotonous decrease in intensity below $x \approx 0.75$ in accordance with the electrochemical lithium de-intercalation from $\mathrm{Li}_{x} \mathrm{CoO}_{2}$. It was suggested that the ${ }^{7} \mathrm{Li}$ NMR shift (Knight shift) for $\mathrm{Li}_{x} \mathrm{CoO}_{2}$ seemed correlated with the interlayer distance between the $\mathrm{CoO}_{2}$ layers, where $\mathrm{Li}^{+}$ions are intercalated. Also, it was clearly observed that the dendritic/mossy lithium increased and decreased in intensity on charging and discharging process, respectively. A small amount of dendritic/mossy lithium was irreversibly left, and grew up with increasing cycle number. We stress that the in situ NMR/MRI (magnetic resonance imaging) monitoring of the dendritic/mossy lithium provides critical information for full understanding the condition of the dendrite formation $[30,36,37]$ that will be also applicable to, for example, lithium-air or lithium-sulfur battery research. This study underscores the potency of in situ ${ }^{7} \mathrm{Li}$ NMR in parallel with electrochemical measurement, which provides quantitative information on lithium environments in cathode, anode, and electrolyte simultaneously. We believe that in situ NMR technique will be a good alternative to be considered to the other in situ analytical tools [38].

\section{Acknowledgments}

This work was supported by the Research and Development Innovative for Scientific Innovation of New Generation Battery (RISING) project from New Energy and Industrial Technology Development Organization (NEDO), Japan. The authors thank Dr. Yukinori Koyama at Kyoto University for his fruitful suggestions, and Mr. Takahiro Kakei for his experimental supports.

\section{Appendix A. Supplementary data}

Supplementary data associated with this article can be found, in the online version, at http://dx.doi.org/10.1016/ j.electacta.2013.06.120.

\section{References}

[1] J.N. Reimers, J.R. Dahn, Electrochemical and in situ X-ray diffraction studies of lithium intercalation in $\mathrm{Li}_{x} \mathrm{CoO}_{2}$, Journal of the Electrochemical Society 139 (1992) 2091.

[2] G.G. Amatucci, J.M. Tarascon, L.C. Klein, $\mathrm{CoO}_{2}$, the end member of the $\mathrm{Li}_{x} \mathrm{CoO}_{2}$ solid solution, Journal of the Electrochemical Society 143 (1996) 1114.

[3] Z. Chen, Z. Lu, J.R. Dahn, Staging phase transitions in $\mathrm{Li}_{x} \mathrm{CoO}_{2}$, Journal of the Electrochemical Society 149 (2002) A1604.

[4] Z. Chen, J.R. Dahn, Methods to obtain excellent capacity retention in $\mathrm{LiCoO}_{2}$ cycled to 4.5 V, Electrochimica Acta 49 (2004) 1079.

[5] N. Sharma, V.K. Peterson, M.M. Elcombe, M. Avdeev, A.J. Studer, N. Blagojevic, R. Yusoff, N. Kamarulzaman, Structural changes in a commercial lithium-ion battery during electrochemical cycling: an in situ neutron diffraction study, Journal of Power Sources 195 (2010) 8258

[6] I. Nakai, K. Takahashi, Y. Shiraishi, T. Nakagome, F. Nishikawa, Study of the Jahn-Teller distortion in $\mathrm{LiNiO}_{2}$, a cathode material in a rechargeable lithium battery, by in situ X-ray absorption fine structure analysis, Journal of Solid State Chemistry 140 (1998) 145.

[7] Y. Koyama, H. Arai, Z. Ogumi, I. Tanaka, Y. Uchimoto, Co K-edge XANES of $\mathrm{LiCoO}_{2}$ and $\mathrm{CoO}_{2}$ with a variety of structures by supercell density functional calculations with a core hole, Physical Review B 85 (2012) 075129.

[8] B. Ouyang, X. Cao, H.W. Lin, S. Slane, S. Kostov, M. denBoer, S.G. Greenbaum, Lithium-7 NMR studies of $\mathrm{Li}_{1-x} \mathrm{CoO}_{2}$ battery cathodes, Materials Research Society Symposium Proceedings 369 (1995) 59.

[9] P. Mustarelli, V. Massarotti, M. Bini, D. Capsoni, Transferred hyperfine interaction and structure in $\mathrm{LiMn}_{2} \mathrm{O}_{4}$ and $\mathrm{Li}_{2} \mathrm{MnO}_{3}$ coexisting phases: A XRD and ${ }^{7} \mathrm{Li}$ NMR-MAS study, Physical Review B 55 (1997) 12018.

[10] M. Ménétrier, I. Saadoune, S. Levasseur, C. Delmas, The insulator-metal transition upon lithium deintercalation from $\mathrm{LiCoO}_{2}$ : electronic properties and ${ }^{7} \mathrm{Li}$ NMR study, Journal of Materials Chemistry 9 (1999) 1135

[11] S. Levasseur, M. Ménétrier, E. Suard, C. Delmas, Evidence for structural defects in non-stoichimetric $\mathrm{HT}-\mathrm{LiCoO}_{2}$ : electrochemical, electronic properties and ${ }^{7} \mathrm{Li}$ NMR studies, Solid State Ionics 128 (2000) 11.

[12] K. Guérin, M. Ménétrier, A. Février-Bouvier, S. Flandrois, B. Simon, P. Biensan $A^{7}$ Li NMR study of a hard carbon for lithium-ion rechargeable batteries, Solid State Ionics 127 (2000) 187.

[13] Y.J. Lee, C.P. Grey, Determining the lithium local environments in the lithium manganates $\mathrm{LiZn}_{0.5} \mathrm{Mn}_{1.5} \mathrm{O}_{4}$ and $\mathrm{Li}_{2} \mathrm{MnO}_{3}$ by analysis of the ${ }^{6} \mathrm{Li}$ MAS NMR spinning sideband manifolds, The Journal of Physical Chemistry B 106 (2002) 3576

[14] M.C. Tucker, M.M. Doeff, T.J. Richardson, R. Fiñones, J.A. Reimer, E.J. Cairns, ${ }^{7} \mathrm{Li}$ and ${ }^{31} \mathrm{P}$ Magic angle spinning nuclear magnetic resonance of $\mathrm{LiFePO}_{4}$-type materials, Electrochemical and Solid-State Letters 5 (2002) A95.

[15] P. Azaïs, L. Duclaux, A.-M. Faugère, F. Béguin, Reactive milling of graphite with lithium: application to lithium batteries, Applied Physics Letters 81 (2002) 775

[16] C.P. Grey, N. Dupré, NMR studies of cathode materials for lithium-ion rechargeable batteries, Chemical Reviews 104 (2004) 4493.

[17] B.M. Meyer, N. Leifer, S. Sakamoto, S.G. Greenbaum, C.P. Grey, High field multinuclear NMR investigation of the SEI layer in lithium rechargeable batteries, Electrochemical and Solid-State Letters 8 (2005) A145.

[18] K. Gotoh, M. Maeda, A. Nagai, A. Goto, M. Tansho, K. Hashi, T. Shimizu, H. Ishida, Properties of a novel hard-carbon optimized to large size Li ion secondary battery studied by ${ }^{7}$ Li NMR, Journal of Power Sources 162 (2006) 1322.

[19] J. Cabana, J. Shirakawa, G. Chen, T.J. Richardson, C.P. Grey, MAS NMR study of the metastable solid solutions found in the $\mathrm{LiFePO}_{4} / \mathrm{FePO}_{4}$ system, Chemistry of Materials 22 (2010) 1249

[20] L.J.M. Davis, I. Heinmaa, B.L. Ellis, L.F. Nazar, G.R. Goward, Influence of particle size on solid solution formation and phase interfaces in $\mathrm{Li}_{0.5} \mathrm{FePO}_{4}$ revealed by ${ }^{31} \mathrm{P}$ and ${ }^{7} \mathrm{Li}$ solid state NMR spectroscopy, Physical Chemistry Chemical Physics 13 (2011) 5171

[21] B. Key, M. Morcrette, J.-M. Tarascon, C.P. Grey, Pair distribution function analysis and solid state NMR studies of silicon electrodes for lithium ion batteries: understanding the (de)lithiation mechanisms, Journal of the American Chemical Society 133 (2011) 503.

[22] M. Murakami, H. Yamashige, H. Arai, Y.Uchimoto, Z. Ogumi, Association of paramagnetic species with formation of $\mathrm{LiF}$ at the surface of $\mathrm{LiCoO}_{2}$, Electrochimica Acta 78 (2012) 49

[23] H. Hain, M. Scheuermann, R. Heinzmann, L. Wünsche, H. Hahn, S. Indris, Study of local structure and $\mathrm{Li}$ dynamics in $\mathrm{Li}_{4+x} \mathrm{Ti}_{5} \mathrm{O}_{12}(0 \leq x \leq 5)$ using ${ }^{6} \mathrm{Li}$ and ${ }^{7} \mathrm{Li}$ NMR spectroscopy, Solid State Nuclear Magnetic Resonance 42 (2012) 9.

[24] R.E. Gerald II, J. Sanchez, C.S. Johnson, R.J. Klingler, J.W. Rathke, In situ nuclear magnetic resonance investigations of lithium ions in carbon electrode materials using a novel detector, Journal of Physics: Condensed Matter 13 (2001) 8269.

[25] M. Letellier, F. Chevallier, C. Clinard, E. Frackowiak, J.-N. Rouzaud, F. Béguin, M. Morcrette, J.-M. Tarascon, The first in situ ${ }^{7} \mathrm{Li}$ nuclear magnetic resonance study of lithium insertion in hard-carbon anode materials for Li-ion batteries, The Journal of Chemical Physics 118 (2003) 6038.

[26] M. Letellier, F. Chevallier, F. Béguin, E. Frackowiak, J.-N. Rouzaud, The first in situ ${ }^{7} \mathrm{Li}$ NMR study of the reversible lithium insertion mechanism in disorganised carbons, Journal of Physical Chemistry of Solids 65 (2004) 245.

[27] M. Letellier, F. Chevallier, F. Béguin, In situ ${ }^{7}$ Li NMR during lithium electrochemical insertion into graphite and a carbon/carbon composite, Journal of Physical Chemistry of Solids 67 (2006) 1228.

[28] M. Letellier, F. Chevallier, M. Morcrette, In situ ${ }^{7} \mathrm{Li}$ nuclear magnetic resonance observation of the electrochemical intercalation of lithium in graphite; $1 \mathrm{st}$ cycle, Carbon 45 (2007) 1025.

[29] B. Key, R. Bhattacharyya, M. Morcrette, V. Seznéc, J.-M. Tarascon, C.P. Grey, Real-time NMR investigations of structural changes in silicon electrodes for lithium-ion batteries, Journal of the American Chemical Society 131 (2009) 9239.

[30] R. Bhattacharyya, B. Key, H. Chen, A.S. Best, A.F. Hollenkamp, C.P. Grey, In situ NMR observation of the formation of metallic lithium microstructures in lithium batteries, Nature Materials 9 (2010) 504.

[31] F. Poli, J.S. Kshetrimayum, L. Monconduit, M. Letellier, New cell design for in situ NMR studies of lithium-ion batteries, Electrochemical Communications 13 (2011) 1293

[32] B. Key, R. Bhattacharyya, H. Chen, C.P. Grey, In-situ solid state NMR studies on high rate lithium-ion batteries, in: The 214th ECS Meeting Abstract, 2008, \#1210. 
[33] C. Kittel, Introduction to Solid State Physics, 8th edn, John Wiley, New York, 2004.

[34] N.M. Trease, L. Zhou, H.J. Chang, B.Y. Zhu, C.P. Grey, In situ NMR of lithium ion batteries: bulk susceptibility effects and practical considerations, Solid State Nuclear Magnetic Resonance 42 (2012) 62.

[35] T. Ohzuku, A. Ueda, Solid-state redox reactions of $\mathrm{LiCoO}_{2}(\mathrm{R}-3 \mathrm{~m})$ for 4 Volt secondary lithium cells, Journal of the Electrochemical Society 141 (1994) 2972.
[36] R.E. Gerald II, R.J. Klingler, G. Sandí, C.S. Johnson, L.G. Scanlon, J.W. Rathke, ${ }^{7}$ Li NMR study of intercalated lithium in curved carbon lattices, Journal of Power Sources 89 (2000) 237.

[37] S. Chandrashekar, N.M. Trease, H.J. Chang, L.-S. Du, C.P. Grey, A. Jerschow, ${ }^{7}$ L MRI of Li batteries reveals location of microstructural lithium, Nature Materials 11 (2012) 311.

[38] S.F. Amalraj, D. Aurbach, The use of in situ techniques in R\&D of $\mathrm{Li}$ and $\mathrm{Mg}$ rechargeable batteries, Journal of Solid State Electrochemistry 15 (2011) 877. 